\title{
AS AVALIAÇÕES DE SOCIOLOGIA NO ENSINO MÉDIO: ALGUMAS REFLEXÕES
}

\author{
Rafaela Reis Azevedo de Oliveira \\ Carolina Ferreira Soares
}

\section{Introdução}

Este capítulo tem como objetivo trazer reflexões sobre as avaliações de aprendizagem realizadas no Ensino Médio na disciplina de Sociologia em Escolas da Rede Estadual de Minas Gerais, localizadas no município de Juiz de Fora. É fruto de uma pesquisa realizada com discentes e docentes do Ensino Médio no âmbito das atividades do Programa Institucional de Bolsas de Iniciação à Docência de Sociologia e das atividades de Estágio Supervisionado realizadas no curso de formação inicial de professores de Sociologia da Universidade Federal de Juiz de Fora. A pesquisa realizada foi feita a partir de um questionário produzido pelos licenciandos, em disciplina de orientação do Estágio Supervisionado, a partir de reflexões sobre as avaliações de aprendizagem e pela própria experiência que puderem ter em organizar, aplicar e corrigir atividades avaliativas nas turmas em que acompanhavam. Tomamos como referencial teórico as reflexões de Luckesi (2011) a respeito da importância de realizar uma avaliação que não puna o estudante, mas que seja formativa e amorosa. Concluímos que, para os discentes do Ensino Médio, tanto as avaliações quanto o processo de verificação de aprendizagem proposto pelos professores possuem uma falta de clareza, podendo muitas vezes gerar ansiedade e/ou desinteresse em realizá-las. Identificamos, ainda, que os estudantes têm preferências muito distintas a respeito do processo avaliativo, o que nos reforça a afirmar sobre a necessidade de que os professores conheçam seus estudantes e proponham atividades avaliativas alinhadas com a teoria pedagógica que guia sua prática docente.

Avaliar, segundo um dicionário de português, é um verbo que pode ser bitransitivo, ou seja, ele necessita de dois complementos, um sem preposição (objeto direto) e outro com preposição (objeto indireto). Ao verificarmos seu significado em dicionários, trouxemos para o texto algumas definições, como: determinar o valor, reconhecer a grandeza, saber o valor ou a importância de alguma coisa. E como sinônimos, encontramos as palavras: calcular, julgar, mensurar, etc. E por que iniciar um texto sobre avaliação de aprendizagem de Sociologia mobilizando essa definição gramatical da palavra avaliar? Porque é sempre importante lembrarmos que o ato de avaliar, pelo seu próprio caráter de dupla transitividade, requer, portanto, que avaliemos o "quem" - professores, alunos, sistemas de ensino -, "para alguém" - os mesmos professores, alunos, sistemas de ensino e, incluímos, pais, sociedade e até organismos internacionais.

*DOI - 10.29388/978-65-86678-86-4-0.f.77-91 
No âmbito da avaliação educacional, há várias dimensões e usos sendo feitos (SOUZA, 2005), mas neste trabalho discutiremos, em especial, a avaliação de aprendizagem, ou seja, aquela que é feita na escola, pelos professores com seus alunos, normalmente, com fins a promoção dentro de uma etapa escolar.

Dito isso, este trabalho tem como objetivo trazer reflexões sobre as avaliações de aprendizagem realizadas no Ensino Médio, na disciplina de Sociologia, em escolas da Rede Estadual de Minas Gerais, do município de Juiz de Fora.

Resultante de uma pesquisa realizada por professores, licenciandos em Ciências Sociais da Universidade Federal de Juiz de Fora (UFJF) e bolsistas do Programa Institucional de Bolsas de Iniciação à Docência (PIBID), teve como justificativa a importância de conhecerem o processo de avaliar, que requer um entrelaçamento com as práticas educativas e, também, o conhecimento prévio dos estudantes do Ensino Médio (LUCKESI, 2011).

Organizamos o artigo com fins a apresentarmos uma breve revisão bibliográfica sobre avaliação educacional e avaliação de aprendizagem; na sequência, os apontamentos metodológicos de como a pesquisa foi realizada; apresentaremos os resultados obtidos pela pesquisa e, finalmente, algumas considerações a respeito do trabalho realizado.

\section{Avaliação educacional}

Esta seção tem como objetivo apresentar breves elementos sobre os processos de avaliação educacional. Num primeiro momento, tratamos sobre as avaliações em larga escala e sobre as avaliações de aprendizagem; num segundo, sobre as avaliações de Sociologia no Ensino Médio.

\subsection{Avaliação Educacional: brevíssimos apontamentos sobre os processos em larga escala e de aprendizagem.}

A temática da avaliação educacional é bastante controversa, sobretudo quando a discutimos no âmbito das avaliações em larga escala, alinhadas com a discussão de bonificação e mecanismos de accountability. Há uma bibliografia muito extensa sobre esses processos, que carregam em si muitas críticas, pois acreditam que, por meio destas avaliações e por índice educacional que utilizam de seus resultados, é realizado um ranqueamento entre escolas e alunos que pode ser mais danoso que efetivamente benéfico. Por outro lado, há uma série de pesquisadores que defendem que o ato de avaliar os educandos e seus sistemas é uma ação de garantia do direito à educação, que conforme previsto no art. 206 da CF/88, tem como princípio a oferta de educação de qualidade (REZENDE et al, 2012). Ou seja, entende-se que ao avaliar o estudante ou seus sistemas de ensino, estão identificando se eles estão tendo uma educação de qualidade, que pressupõe o cumprimento de seus objetivos educacionais (GUSMÃO, 2013). Mas como apontamos no texto introdutório, avaliar requer sempre identificar o "quê" ou "quem" e "para 
quem" ou "para quê", portanto, vamos pensar, neste primeiro momento, para quem ou para quê ela serve.

Simon Schwartzman (2005, p. 15), analisando as avaliações da nova geração, aponta que "Educação e avaliação sempre andaram de mãos dadas. O trabalho do educador é transformar o estudante naquilo que não era [...]" e que para tanto, os educadores precisam da ferramenta de avaliar de modo a saber se seus estudantes estão progredindo neste processo.

Traçando um percurso histórico, Schwartzman destaca que os sistemas de avaliação educacional se desenvolveram, sobretudo naqueles Estados que assumiram a centralidade da oferta e do financiamento de uma Educação Básica, como é o Estado brasileiro, (CF/88, art. 205). Esses sistemas de avaliação buscam criar padrões de desempenho que estão alheios às preferências de professores e/ou escolas e foram pensados mediante a ampliação da abrangência educacional, visto que em sistemas mais tradicionais, o "controle" sobre o processo educativo e sobre o aprendizado do estudante era mais fácil. Contudo, quando o sistema se diferencia (educação vocacional, científico, geral, profissional) e amplia sua oferta (ampliação da obrigatoriedade e gratuidade) foi possível observar baixos desempenhos dos estudantes.

No âmbito da Educação Básica, o autor destaca dois níveis de avaliação: low states e high stakes. A primeira visa avaliar e certificar o aluno; já a segunda, diagnosticar a qualidade do ensino. No Brasil, como é amplamente conhecido, nosso modelo high stakes é o Sistema de Avaliação da Educação Básica (SAEB), existente desde 1990, e que segue a metodologia de avaliar uma amostra de estudantes de escolas públicas e privadas de todo o país, com fins a obter informações sobre o desempenho acadêmicos dos brasileiros. Como não é nossa intenção aprofundar, neste texto, as características, as críticas negativas e positivas a respeito das avaliações em larga escola, deixamos apenas algumas questões para serem pensadas a respeito destas avaliações: estariam os estudantes e os professores se preparando apenas para essas avaliações? Estariam os professores utilizando as matrizes de referências destas avaliações como currículo escolar? Os estudantes reconhecem os objetivos e suposta importância destas avaliações? Fazem-nas com fidedignidade? As avaliações são tendenciosas? Elas captam as realidades dos estudantes, de seus professores e de suas escolas? É possível fazer um uso pedagógico destes testes high stakes?

Cumpre dizer que high stakes e low stakes são níveis de avaliação, mas dentro delas é possível identificarmos os diferentes tipos de avaliação (LUCKESI, 2011), como: a avaliação diagnóstica está mais presente nas avaliações em larga escala, que pelo próprio nome já indica a intenção de realizar um diagnóstico sobre um aluno, uma turma ou um sistema e, quando realizada no nível da avaliação de aprendizagem, normalmente é feita no início do ano ou semestre letivo de modo a planejar as atividades docentes; há as avaliações formativas, que têm como objetivo informar estudantes e professores sobre o progresso escolar diário; as avaliações somativas, que tem como objetivo classificar os alunos ao final de uma unidade, semestre ou ano letivo, geralmente acompanhando de um resultado (aprovado, reprovado, 
classificado, etc), que também pode estar presente em avaliações em larga escala que usam o critério de classificação para ingresso no ensino superior, por exemplo; e dentre outras, a autoavaliação, que é uma prática de colocar o sujeito na condição avaliar-se sobre suas aptidões, atitudes e sobre o êxito em relação aos seus objetivos.

Como já destacamos em outro momento, nosso objetivo é adentrar nas discussões sobre avaliação de aprendizagem. E que tipo de avaliação de aprendizagem estamos assumindo?

Assumimos a avaliação de aprendizagem a partir da perspectiva teórica de Cipriano Luckesi (2011), que a defende como um recurso pedagógico bastante útil, mas para que assim a seja, não pode ser ameaçadora, classificatória, mas amorosa, inclusiva, dinâmica e construtiva.

Luckesi nos faz pensar sobre o processo de avaliar o aluno nos colocando a seguinte questão: estou disposta a acolher? Em suas palavras: "Avaliar um educando implica, antes de mais nada, acolhê-lo no seu lar e no seu modo de ser, como está, para, a partir daí, decidir o que fazer" (LUCKESI, 2000, p. 1).

Destaca que o ato de avaliar não é um ato de atribuir simplesmente uma nota a alguém (os nossos objetos direto e indireto "quê" e "para quem"). Avaliar é um processo, que envolvem duas etapas articuladas e indissociáveis, como o diagnóstico e a decisão, e que, portanto, a atribuição da nota deve significar, em última instância, apenas uma exigência do sistema. Afirma, ainda, sobre a importância de que professores sempre reflexionem sobre seus instrumentos de avaliação: eles estão servindo como coleta de dados sobre a aprendizagem dos alunos, ou como recursos disciplinar e ameaçador?

\subsection{A Sociologia nas avaliações educacionais}

Discutir as avaliações de Sociologia no Ensino Médio não é tarefa fácil, visto que há pouquíssimas pesquisas e estudos publicados retratando a temática. Analisando inúmeras publicações físicas e eletrônicas que tratam especialmente sobre o ensino de Sociologia no Ensino Médio, identificamos apenas discussões em torno das avaliações em larga escala, estaduais e nacional, mas, principalmente, sobre as questões de Sociologia no Exame Nacional do Ensino Médio (Enem) e sobre o uso do componente curricular de Sociologia para auxiliar na realização das redações do referido exame.

Alexandre Lima (2017, p. 131-2), por exemplo, apresenta uma pesquisa realizada sobre a Sociologia nas matrizes curriculares do Ensino Médio e no Enem, em que, a partir da análise de 19 propostas curriculares estaduais, pode identificar que há uma consonância entre as propostas e a presença da Sociologia no Exame, que segundo ele, tem caracterizado o discurso sociológico nas escolas, "no qual certos conceitos e temas têm grande visibilidade enquanto outros são menos trabalhados ou até silenciados". Nesta pesquisa, foram identificadas "900 menções a 318 conceitos diferentes; 418 menções a temas diferentes e 201 referências a 102 autores diferentes" do campo da Sociologia. E foi com base nessa pesquisa inicial que ele 
mirou no Enem para identificar se havia reconhecimento da Sociologia escolar no Exame.

Antes de apresentarmos brevemente o resultado final desta pesquisa, é forçoso lembrar que o Enem, vigente desde 1998, contou com a presença oficial dos conteúdos de Sociologia em seu eixo de Ciências Humanas somente a partir de 2009, um ano após a consolidação da Sociologia como disciplina obrigatória dos currículos escolares do Ensino Médio (BRASIL, 2006). Anteriormente, a Sociologia constava como conteúdo transversal obrigatório a ser estudado nesta etapa final da Educação Básica.

Analisando os itens das provas em sua primeira década de Exame (1998 a 2008), Lima identificou os conceitos, temas e referências do campo da Sociologia em um total de 80 itens, ou um percentual variável entre $5 \%$ a $17 \%$ do total de itens da prova no período.

Em 2008, com as alterações ocorridas no Enem, que deixa de ser apenas uma avaliação diagnóstica do Ensino Médio, para também atender maioria das universidades públicas e privadas para o ingresso no Ensino Superior, "a prova deixou de ser caracterizada como essencialmente multidisciplinar para tornar-se um teste marcado pela forte classificação e maior isolamento das disciplinas, incluindo nesse processo a sociologia" (LIMA, 2017, p. 136). Assim, entre os anos de 2009 a 2015, tendo sido a prova reorganizada em 4 áreas de conhecimento com 45 itens cada, pode-se identificar na área de Ciências Humanas uma mudança significativa para a Sociologia. Ela passou a constar em cinco das seis competências da área; em 19 das 30 habilidades; e em três dos cinco objetos de conhecimento. Foi possível destacar, ainda, que o componente curricular de Sociologia realiza transdisciplinaridade com história e geografia, tendo ficado a filosofia com enquadramento mais rígido; novos temas e novos objetos de conhecimento, bem como questões mais polêmicas e de repercussão no debate público, sobretudo nos temas da redação, eram mais facilmente acolhidos pela Sociologia. Identificou-se, finalmente, que no período, a Sociologia esteve presente em 174 itens da prova, variando entre $9 \%$ a $17 \%$ do total de itens do Exame. Cumpre destacar que foi no ano de 2010 que a pesquisa identificou o maior número de itens com conteúdo sociológico, um total de 30 em 45 da área de Ciências Humanas, e o percentual de 17\% em relação ao total da prova.

Lima concluía seu estudo atentando para o fato de que caso o Enem mantivesse sua estrutura e seguisse a tendência identificada por ele, o lugar da Sociologia estaria garantido no Exame. Contudo, ele foi bastante certeiro, em vista dos acontecimentos que se seguiram - reforma do novo Ensino Médio; Sociologia deixando de ser disciplina obrigatória e constando como conteúdo na Base Nacional Comum Curricular do Ensino Médio (BRASIL, 2018), ao afirmar que mediante o arrefecimento da cidadania "e novas guinadas curriculares, desta vez no sentido da obliteração dos grupos historicamente silenciados e do obscurantismo a respeito da vida social acontecerem, seu lugar estará novamente na berlinda" (LIMA, 2017, p. 147). 
Laura Rossi (2017) também apresenta pesquisa sobre a Sociologia em avaliação em larga escala, mas desta vez o foco está nas avaliações estaduais. Conforme destaca a pesquisadora, a Sociologia consta nas avaliações de três estados brasileiros, a saber: Amazonas, com o Sistema de Avaliação do Desempenho Educacional do Amazonas (SADEAM); a Bahia, com o Sistema De Avaliação Baiano de Educação (SABE); e o Cerará, com o Sistema Permanente de Avaliação da Educação Básica do Ceará (SPAECE).

Olhando para os resultados dessas avaliações, Rossi (2017, p. 161) identificou que os estudantes, de uma maneira geral, respondem bem a itens que avaliam "competências que dizem respeito à prática e à representação política, às desigualdades sociais e econômicas, às noções de cidadania, de globalização e de cultura", ou seja, competências mais simples, visto que estão mais presentes no imaginário social compartilhado pelos estudantes e que se ancoram em padrões baixos de desempenho. Por outro lado, os itens que avaliam competências que se ancoram em padrões de desempenho mais alto, que não fazem parte do cotidiano do estudante, são menos acertados. Isso significa, portanto, que os estudantes do Ensino Médio, a dizer pelos resultados destas avaliações, possuem dificuldades em aprender competências que

[...] dizem respeito à capacidade de 'reconhecer as características que produzem hierarquias sociais', de compreender 'o caráter multicultural da sociedade brasileira', a 'importância das instituições sociais para a manutenção da estabilidade social', a 'importância dos movimentos sociais como forma de intervenção na estrutura social', e a 'relação os meios de comunicação de massa com a vida cotidiana' (ROSSI, 2017, p. 161).

Dados como esses são bastante interessantes de serem investigados no dia a dia da sala de aula, podendo afirmar, aqui, um dos efeitos positivos de se realizar uma avaliação em larga escala. Seria fazer o uso pedagógico dos testes, mas num processo de aperfeiçoamento e não tomada do exame como currículo e treino, como é possível reconhecer em diversas realidades brasileiras.

Mas e as avaliações de desempenho em Sociologia? Como havia informado, não identificamos pesquisas e estudos sobre a temática, mas é possível trazer algumas hipóteses que estão atreladas à forma como muito estudantes visualizam a disciplina.

Historicamente, a disciplina foi considerada bastante maçante pelos estudantes, visto que ela carrega uma carga de leitura que se destaca em meio as demais que são obrigatórias no Ensino Médio (OLIVEIRA; ANTUNES, 2017). Há atrelado a isso, uma geração de professores que lecionam o conteúdo de maneira conteudista e pouco contextualizada, tendo em vista uma tradição mais bacharelesca da área de Ciências Sociais (SARDINHA, 2015). Tais posturas têm sido repensadas, felizmente, incluindo diferentes suportes para auxiliar nos estudos de Sociologia, que se favoreceu com a entrada da disciplina no Programa Nacional do Livro Didático 
(PNLD) em 2012; a emergência de inúmeros laboratórios de ensino e blogs de Sociologia que oferecem materiais de apoio - textos, vídeos, indicação de filmes, músicas, poesias, etc., de forma a dinamizar o conteúdo e torná-lo mais acessível e atrativo ao público jovem do Ensino Médio, bem como cursos de formação continuada de professores.

É forçoso considerar, também, uma perspectiva mais pragmática do estudante do Ensino Médio, haja vista que ao não ser cobrado o conteúdo em vestibulares, programas de ingressos modulares e, oficialmente, no Enem, muitos não se dedicavam à disciplina. Um exemplo é o Programa de Ingresso Seletivo Misto (PISM) da UFJF. A Sociologia está presente apenas no Módulo III, realizado pelos estudantes do 3 o ano do Ensino Médio e que desejam ingressar na área de Ciências Humanas Sociais e Aplicadas.

Analisando provas ou atividades avaliativas de Sociologia da rede pública estadual e federal e, enquanto professoras de Sociologia no Ensino Médio, orientadora de estágio supervisionado e bolsista do PIBID, pudemos observar que as avaliações de aprendizagem de Sociologia, normalmente, são realizadas por meio de provas com questões optativas e discursivas em que são explorados textos, charges, músicas e questões de vestibulares ou Enem, selecionados na internet. Também é prática comum a atribuição de uma atividade de pesquisa, individual ou em grupo, com apresentação dos resultados em seminários; e finalmente, também identificamos com certa frequência a atribuição de notas pelo visto no caderno, ou seja, quando o aluno copia a matéria do quadro no caderno, o professor premia com uma nota, com a justificativa de ser uma forma do estudante reter atenção na aula. Mas se estamos trabalhando com a ideia de avaliação acolhedora, o que os docentes e discentes pensam disso?

\section{0 percurso da pesquisa}

A pesquisa que apresentamos foi idealizada no âmbito das disciplinas Reflexões no Espaço Escolar II - Ensino de Sociologia, e de sua prática atrelada, Estágio Supervisionado no Ensino de Sociologia II realizadas no curso de licenciatura em Ciências Sociais, na Faculdade de Educação da UFJF.

Nesta disciplina, a professora realiza parceria com, pelo menos, três professores do Ensino Médio, a cada semestre, de modo que estes, ao assumirem a supervisão dos estudantes estagiários, possam também participar das atividades de discussão e pesquisa na Universidade e que as visitas às escolas possam ser mais fortalecidas. Desta forma, no segundo semestre de 2019, foram feitas parcerias com três escolas estaduais, localizadas na região central e zona norte da cidade, sendo que para este trabalho mobilizamos os dados de duas escolas (Escola A e Escola B), considerando o maior número de alunos estagiários. Cada escola tinha um professor de Sociologia, supervisor de estágio. Um deles também é supervisor do PIBID de Sociologia. 
A escola A é uma escola urbana, localizada na região central da cidade. Funciona num prédio de estrutura bastante precária, que não atende aos padrões de acessibilidade. Recebe estudantes dos anos finais do Ensino Fundamental (EF), Ensino Médio e Educação Especial. De acordo com os dados do QEdu de 2018, a escola possui 180 alunos matriculados nos anos finais do EF, 426 alunos do Ensino Médio e um total de 72 funcionários. Dentre eles, apenas um professor de Sociologia. Sobre os dados do Ensino Médio, a taxa média de aprovação é 74,5\%. A Taxa de participação dos estudantes no Enem é de $44 \%$, sendo que a média na área de Ciências Humanas é 556 pontos.

A Escola B é uma escola urbana, localizada na região central da cidade. Funciona num prédio histórico e bem estruturado, atendendo aos padrões de acessibilidade. Recebe estudantes dos dois ciclos do Ensino Fundamental, Ensino Médio, EJA e Educação Especial. De acordo com os dados do QEdu de 2018, a escola possui 461 alunos no primeiro ciclo do EF; 616 no segundo ciclo do EF; 1249 alunos matriculados no Ensino Médio; 273 na Educação de Jovens e Adultos; e 39 estudantes da Educação Especial e um total de 255 funcionários. Dentre eles, três são os professores de Sociologia. Sobre os dados do Ensino Médio, a taxa média de aprovação é de 70,8\%. A taxa de participação dos estudantes no Enem é de $47 \%$, sendo que a média na área de Ciências Humanas é de 567 pontos.

O professor da Escola A é formado em Ciências Sociais e especialista em Métodos Estatísticos Computacionais. É concursado da Rede Estadual de Minas Gerais desde 2012, inicialmente em Belo Horizonte, onde também atuou como supervisor do PIBID; atualmente, leciona em Juiz de Fora. A lotação na escola A é recente, desde o segundo semestre de 2018.

O professor da Escola B, além de formado em Ciências Sociais, também possui licenciatura em Letras. É mestre em Estudos Literários e atualmente é doutorando na mesma área. É concursado na área de Sociologia da Rede Estadual de Educação de Minas Gerais desde 2013 e esteve supervisor do PIBID de Sociologia no momento da pesquisa.

A proposta feita pela docente da UFJF foi que os licenciandos, acompanhados de seus supervisores nas escolas, pudessem observar, entre outras coisas, as práticas de avaliação discente realizadas na disciplina de Sociologia ao longo do bimestre/semestre, mas que também pudessem propor uma atividade avaliativa posterior à regência realizada por cada um dos futuros professores.

Essas atividades, previamente organizada junto com a referida docente e os supervisores de Estágio, foram previamente aprovadas e serviram de pontuação para o bimestre do aluno do Ensino Médio. Além disso, os licenciados tiveram como tarefa a correção e atribuição de nota de suas atividades.

Uma última atividade foi a aplicação de um questionário aos discentes das escolas e também aos docentes. Ambos questionários foram criados durante as aulas da disciplina de Reflexões do Espaço Escolar II - Ensino de Sociologia, partindo de um brainstorm sobre questões que os estudantes gostariam de saber sobre o processo de avaliação de aprendizagem, com base nas discussões teóricas que já havia sido feito. 
O questionário dos estudantes teve 18 questões discursivas e optativas e foi aplicado em momentos finais da aula, com a anuência dos professores. Já o questionário com os dois professores contém 11 questões dissertativas, tendo sido enviado por e-mail e retornado diretamente aos licenciandos. Os dados que seguem são, portanto, uma compilação dos relatórios finais de estágio dos estudantes.

\section{O que dizem alunos e professores sobre as avaliações de aprendizagem em sociologia do ensino médio?}

\subsection{Avaliação de aprendizagem e os discentes do Ensino Médio}

Ouvir os discentes sobre o processo avaliativo nos pareceu fundamental se defendemos uma docência acolhedora em seu ato de avaliar, tal como Luckesi defende. Portanto, buscamos no questionário captar uma série de sensações, preferências, expectativas e práticas de estudos dos estudantes das duas escolas. Iniciamos, portanto, o questionário investigando sobre a forma como o aluno se sente ao realizar uma prova de Sociologia. Essa questão teve a intenção de captar se o ato de ser avaliado gerava ansiedade no estudante. Embora haja pela maioria dos estudantes tranquilidade, identificamos um percentual de quase $25 \%$ de estudantes que se sentem ansiosos e irritados.

Analisando o grau de frequência dos estudantes que afirmaram estudar antes de uma atividade avaliativa de Sociologia, identificamos em ambas as escolas que menos de $10 \%$ disseram estudar "muito frequentemente".

Um conjunto de seis questões buscaram avaliar o grau de confiança dos estudantes em realizar as seguintes atividades avaliativas: (i) prova de múltipla escolha, (ii) prova dissertativa, (iii) prova de múltipla escolha e dissertativa, (iv) atividades avaliativas feitas em casa individualmente (trabalhos, pesquisas, etc), (v) ou coletivamente, e (vi) atividades feitas em sala de aula (apresentação de seminários, debates, júri-simulado, etc).

Na tabela 1 é possível verificar os resultados das duas escolas sobre estas seis questões. Cumpre mencionar que a escala likert utilizada para elas foram: pouco seguro, indiferente e inseguro.

Tabela 01 - Sobre sentir-se "pouco seguro" na realização das atividades

\begin{tabular}{c|c|c}
\hline Questão & Escola A & Escola B \\
\hline i & $40 \%$ & $46 \%$ \\
\hline ii & $30 \%$ & $35 \%$ \\
\hline iii & $20 \%$ & $44 \%$ \\
\hline iv & $40 \%$ & $17 \%$ \\
\hline v & $30 \%$ & $24 \%$ \\
\hline iv & $30 \%$ & $40 \%$ \\
\hline
\end{tabular}

Fonte: elaborada pelas autoras 
Na tabela 1, destacamos os percentuais relativos à resposta "pouco seguro", considerando que ela configurou a maioria em quase todas. Destacamos, contudo, um dado que diverge de forma significativa entre as escolas, que é relativa a iv, visto que na escola B, a maioria dos estudantes (75\%) respondeu ser "indiferente" sobre a prática individual de realizar atividades de pesquisa e/ou trabalhos em casa.

Outro dado que julgamos importante coletar foi sobre a forma como o aluno prefere receber os resultados de suas atividades avaliativas. Tal questão foi motivada pela observação dos bolsistas do PIBID que relataram o desconforto dos estudantes, quando o professor falava oralmente o resultado em voz alta, nome por nome. Neste sentindo, tanto na Escola $A$, quanto na Escola $B$, os estudantes têm preferência pela divulgação individual das notas, sem que os demais estudantes escutem. Um dado que nos chama a atenção na mesma questão é que uma parcela menor, mas significativa dos estudantes das duas escolas afirmou preferir que os professores corrijam as atividades avaliativas em sala de aula. Esta é uma prática que pode ser bastante interessante, pois o professor tem a chance de ir esclarecendo dúvidas na resolução da prova e até mesmo pode observar como os estudantes recepcionam determinado tipo de questão ou atividade.

Interessante notar que, questionados se as atividades avaliativas contribuem para o aprendizado, a maioria dos estudantes, nas duas escolas, afirmou que sim, que contribuem. Curiosa essa resposta, pois para que uma atividade cumpra essa importante missão, os estudantes deveriam dedicar-se ao estudo e preparo para a sua realização, o que já demonstramos que poucos a fazem.

Em outras três questões, nossa preocupação foi saber se os estudantes, de maneira geral, possuem clareza a respeito do que é pedido nas atividades avaliativas. Desta forma, pedimos que apresentassem o grau de concordância sobre: (i) entender claramente os enunciados das atividades; (ii) entender perfeitamente o vocabulário/ linguagem das atividades avaliativas; e (iii) clareza sobre as orientações que é preciso realizar na atividade (relacionar, explicar, dissertar, etc). A escala likert utilizada considerou: discordo totalmente, discordo, indeciso, concordo e concordo totalmente.

Tabela 02 - Sobre concordar totalmente com as afirmativas acima

\begin{tabular}{c|c|c}
\hline Questão & Escola A & Escola B \\
\hline i & $11 \%$ & $11 \%$ \\
\hline ii & $19 \%$ & $13 \%$ \\
\hline iii & $39 \%$ & $8 \%$ \\
\hline
\end{tabular}

Fonte: elaborada pelas autoras

Destacamos os dados sobre "concordar totalmente" por entendermos que seria o ideal dentro de uma atividade avaliativa. Ou seja, seria de fundamental importância que os estudantes tivessem total clareza sobre a linguagem, o que é para fazer e sobre os enunciados. Contudo, como percebemos, o percentual de estudantes nas duas escolas que concordaram totalmente com as afirmativas é bem baixa, 
denotando, portanto, a necessidade de que professores se atentem para esta questão, visto que certamente o desempenho acaba sendo prejudicado e o conteúdo, por consequência, se torna desinteressante para o jovem.

Os estudantes, de maneira geral, ao serem questionados pelas preferências de suportes nas atividades avaliativas (charges, gráficos, poesias e músicas, tabelas e textos) a maioria afirma preferir atividades que contenham textos, o que para os licenciandos chegou a ser um pouco contraditório, visto que os jovens do Ensino Médio estão, nas escolas observadas, em grande parte envolvidos com grupos de músicas, rap, slam, etc. As hipóteses apresentadas nos relatórios finais de estágios é que muitas músicas trazidas para as provas e aulas são contemporâneas aos professores e não aos estudantes.

Finalmente, deixamos duas questões dissertativas de modo que eles pudessem expressar "o que são as atividades avaliativas na escola" e caso fossem professores de Sociologia "como avaliariam seus alunos e alunas". Na primeira, observamos que a percepção das atividades avaliativas é para medir a inteligência de alguém, mas que isso não é suficiente e "sem grandes necessidades", pois "as avaliações nem sempre avaliam o nível de inteligência de alguém. Uma pessoa pode ter um QI muito elevado, mas não se dar bem em provas e avaliações", pois às vezes fica ansiosa ou nervosa. No que compete a segunda questão, muitos mencionaram que se valeriam de métodos bastante praticados por eles: provas e trabalhos. $E$ houve respostas que disseram, de maneira geral, que não atribuiriam notas, mas conceitos por comportamento e participação em sala de aula.

\subsection{A avaliação de aprendizagem e os professores de Sociologia}

Quando decidimos entrevistar os professores tivemos a intenção de captar se eles se fazem o exercício de acolher o estudante em suas necessidades, o que pensam sobre $o$ ato de avaliar e avaliar na disciplina de Sociologia.

É importante destacar que na Rede Estadual de Minas Gerais, até 2019, os professores de Sociologia tinham apenas 01 tempo de aula semanal com cada série do Ensino Médio, mas que a partir de 2020, com nova portaria publicada pela Secretaria de Estado da Educação de Minas Gerais, as aulas de Sociologia serão distribuídas da seguinte forma: dois tempos de aula semanal no 1 o ano do Ensino Médio e um tempo de aula semanal no 30 ano do Ensino Médio, ficando portanto o 2ㅇ ano sem a oferta da disciplina.

Essa questão importa ser dita, pois os dois professores entrevistados relataram exigências burocráticas mesmo em tão pouco tempo de aula com cada turma. Como Luckesi já aqui citado diz: nota é uma exigência do sistema e realizar um número de atividades por bimestre é um dever de cada professor, tendo uma ou cinco aulas semanais com a sua turma.

Esse "desgaste" burocrático fica muito claro na fala do professor da Escola A. 
A rotina burocratizada se sobrepõe ao desfecho das aulas. Ao longo do ano letivo eu priorizo as atividades em sala de aula e tarefas para casa com correções feitas diante de todos, enquanto que apenas as avaliações e trabalhos são feitas em casa. $O$ controle da chamada, do conteúdo lecionado, das atividades a serem dadas, das avaliações e prazos para serem cumpridos, deixa a rotina do professor de sociologia bastante engessada, pois em média são cinco a seis aulas para desenvolver o tema. Para, além disso, outro aspecto que se sobrepõe ao trabalho enquanto professor é a quantidade de turmas, isso faz com que o mínimo a ser cumprido seja muito a ser realizado. Não é incomum a estafa mental entre os professores de sociologia, no que se refere não somente ao número de avaliações, mas também ao desgaste físico e sobretudo mental (PROFESSOR ESCOLA A, entrevista cedida no dia 22 de novembro de 2019).

Os professores de Sociologia da rede estadual mineira, quando possuem duas matrículas de $24 \mathrm{~h}$, podem chegar a ter 32 turmas/ 32 tempos de aula semanais. 0 professor da Escola A é um exemplo deste feito. Afirmamos como feito, pois acreditamos que essas estão longe de ser as condições ideais de trabalho de um professor, que precisa estudar, pesquisar, planejar e lecionar.

Diante de um cenário de muitas turmas, os professores afirmaram usar ocasionalmente as mesmas atividades avaliativas em diferentes turmas da mesma escola ou quando também atuam em escolas diferentes. A dificuldade de estar sempre preparando uma atividade nova, adequada à turma, considerando o pouco tempo, acaba refletindo esse cenário.

Eles divergiram quanto à forma de divulgação dos resultados. Enquanto o professor da Escola B realiza a entrega das notas em voz alta aos estudantes, o professor da Escola A diz entregá-las individualmente, sendo que já tentou corrigi-las dentro de sala de aula, mas relatou ser uma ação bastante desgastante.

Ambos dão liberdade e tempo para que os estudantes os procurem em caso de dúvidas sobre trabalhos a serem entregues ou conteúdos da prova e isso pode ser por nós observado na prática.

Cumpre, finalmente, destacar que o professor da Escola A ressalta a importância de que as avaliações sejam adaptadas ao passar dos anos do Ensino Médio, dando preferência para atividades escritas no 1으. ano. Ressalta também que é possível haver outro tipo de avaliação que não essas tradicionais, que são comumente realizadas, mas que é preciso haver uma interlocução verdadeira entre os evolvidos e uma pactuação sobre os objetivos educacionais ali postos.

\section{Considerações finais}

Este capítulo teve como objetivo apresentar reflexões sobre o processo de avaliação de aprendizagem na disciplina de Sociologia no Ensino Médio. Para tanto, 
mobilizou um breve referencial teórico que apresentasse ao leitor o que é o ato de avaliar no campo educacional. Sem a intenção de aprofundar sobre as avaliações em larga escala, apresentou as suas diferenças em relação a avaliação de aprendizagem e, na sequência, como os estudos no campo do ensino de sociologia têm retratado a temática. Como foi possível perceber, a discussão em torno da avaliação educacional no campo da sociologia do ensino médio está mais restrita às avaliações em larga escala.

Assim sendo, este artigo trouxe um pequeno relato de pesquisa realizada por professores, licenciados (agora, já formados) do curso de Ciências Sociais da UFJF e também bolsistas do PIBID de Sociologia, que experienciaram a prática de elaborar, aplicar e corrigir uma atividade avaliativa, mas que imbuídos do espírito da "docência acolhedora", foram atrás de investigar o que os estudantes do Ensino Médio pensam sobre as avaliações de aprendizagem de Sociologia, bem como os professores supervisores de seus estágios.

Há uma série de dados que merecem ser melhor aprofundados, mas por hora, e por razão do curto espaço, deixamos indicado que, no geral, os estudantes optam por escolhas mais "tradicionais" que pudéssemos imaginar, quando se tratam de avaliações e de se colocarem na situação de avaliar. Nossa hipótese inicial é que estão "moldados" num padrão de escolarização passiva, cujo professor deposita o conhecimento e os estudantes testam se o "decoraram" através dos testes, que qualquer abordagem distinta ainda gera estranhamento.

Outra questão que merece um aprofundamento é sobre a compreensão que os estudantes têm do que é pedido na atividade avaliativa. Como vimos, a clareza é bastante aquém do desejado. Isso fez lembrar de uma experiência interessante vivida por uma das autoras, que percebeu durante a aplicação das atividades, que muitos estudantes encontravam dificuldades de vocabulário, que atrapalham a compreensão do que estava sendo solicitado a fazer e acabavam falhando. Infelizmente, os comandos nem sempre são claros e quando eles envolvem mais de uma competência, como ler, interpretar, relacionar, dissertar e comparar pode gerar bastante dificuldades para alunos que carregam problemas estruturais em sua formação e que chegam no Ensino Médio com dificuldades de leitura, escrita, interpretação de textos, de imagens, de gráficos, etc. Uma abordagem adotada, neste caso, foi inserir um vocabulário em cada prova, que contivesse o significado de uma forma bem clara e simples. O resultado foi bastante positivo.

Finalmente, um ponto que merece bastante atenção está relacionado com as condições que os professores atuam. $O$ excesso do número de turmas (com fins a um salário que os permita sobreviver) e até deficiências no processo de formação a respeito da temática da avaliação educacional, acaba por dificultar até mesmo abordagens mais acolhedoras e pertinentes nesse processo, que afirmamos útil, mas ainda problemático, que é o ato de avaliar! 


\section{Referências}

BRASIL. CNE/CEB. Parecer no 38 de 07 de julho de 2006. Dispõe sobre a inclusão obrigatória das disciplinas de filosofia e sociologia no currículo do ensino médio. Disponível em: http://portal.mec.gov.br/cne/arquivos/pdf/pceb038_06.pdf. Acesso em: 30 abr. 2016.

BRASIL. Constituição da República Federativa do Brasil de 1988. Disponível em: http://www.planalto.gov.br/ccivil_03/constituicao/constituicaocompilado.htm. Acesso em: 17 de março de 2013.

GUSMÃO, Joana Buarque de. A Construção da noção de qualidade da educação. Ensaio: aval. pol. públ. Educ., Rio de Janeiro, v. 21, n. 79, p. 299-322, abr./jun. 2013. Disponível em: http://www.scielo.br/pdf/ensaio/v21n79/07.pdf. Acesso em: 26 jan. 2020.

LIMA, A. J. C. A Sociologia nas matrizes curriculares do Ensino Médio e no ENEM: temas, teorias e conceitos. In: SILVA, I. F; GONÇALVES, D. N. (orgs). A sociologia na Educação Básica. São Paulo: Annablume, 2017

LUCKESI, C. O que é mesmo o ato de avaliar a aprendizagem? Pátio. Porto Alegre: ARTMED. Ano 3, n. 12 fev./abr. 2000

LUCKESI, C. Avaliação da aprendizagem escolar: estudos e proposições. 22 ed. - São Paulo: Cortez, 2011.

OLIVEIRA, R. R. A.; ANTUNES, K. C. V. A Sociologia no Ensino Médio: com a palavra os estudantes. Revista Teoria e Cultura, v. 12, p. 163-173, 2017

QEDU. Fundação Lemann e Meritt (2017). Portal QEdu.org.br. Disponível em: https://www.qedu.org.br/. Acesso em: 11 nov. 2019.

REZENDE, W.S; DULCI, J. A et al. Avaliação educacional e autonomia no contexto federalista: uma discussão a partir dos sistemas estaduais de avaliação. Pesquisa e Debate em Educação. Juiz de Fora: UFJF, V.2, n.1 (jan./jun. 2012), 2012.

ROSSI, L. A. B. Desafios do ensino de Sociologia na escola pública brasileira: um olhar a partir de resultados da avaliação em larga escala. In: SILVA, I. F; GONÇALVES, D. N. (orgs). A sociologia na Educação Básica. São Paulo: Annablume, 2017 
SARDINHA, A.C.S.; SOUSA, M.P.; FREIRE, T. P. Formação de habitus docente em ciências sociais na UFMA. In: HANDFAS, Anita; MAÇAIRA, Júlia Polessa; FRAGA, Alexandre Barbosa (org.). Conhecimento escolar e ensino de sociologia: instituições, práticas e percepções. 1 ed. - Rio de Janeiro: 7letras, 2015.

SCHWARTMAN, S. As avaliações da nova geração. In: SOUZA, A. de M. e (org.) Dimensões da avaliação educacional. Petrópolis, RJ: Vozes, 2005.

SOUZA, A. de M. e (org.) Dimensões da avaliação educacional. Petrópolis, RJ: Vozes, 2005. 